\title{
SHOREWARD SAND TRANSPORT OUTSIDE THE SURFZONE, NORTHERN GOLD COAST, AUSTRALIA
}

\author{
D. C. Patterson
}

To date, no suitable theoretical basis has been derived to predict with reliable accuracy the shoreward sand transport under waves in the deeper water outside the surf zone. This is important for understanding the rate of recovery of beaches after major storm erosion and, in some circumstances, to quantify net shoreward supply of sand to the shoreline from the active lower shore-face below the depth of storm erosion bar development. Even a relatively low rate of long term shoreward net supply may contribute to shoreline stability where it offsets a gradient in the longshore sand transport that would otherwise lead to recession. This paper outlines the results of analysis of a 41 year dataset of beach and nearshore profile surveys to quantify annual average rates of shoreward net sand transport in 6-20m water in an area where the profiles are not in equilibrium due to the existence of a residual river mouth ebb delta bar lobe. Additionally, an empirical adaptation of the sheet flow relationship of Ribberink and Al-Salem (1990) to provide for the effects of ripples has been derived from large wave flume data and correlates well with the measured Gold Coast transport rates. These have been applied to a new coastline modelling system developed as part of research into the long term evolution of Australia's central east coast region in response to sea level change and longshore sand transport processes, which combines the one-line concept of shoreline profile translation within the zone of littoral sand transport with cross-shore profile evolution across the deeper shore-face profile below that zone. It demonstrates the importance of providing for both the shoreward supply from the continental shelf and the varying profile response time-scale across the shore-face in predicting shoreline evolution.

Keywords: cross-shore sand transport; equilibrium beach profile; profile evolution; profile response time-scale

\section{INTRODUCTION}

\section{Background}

A new modeling capability has been developed by the writer to simulate the long term geologic and contemporary shoreline evolution along Australia's central east coast (Figure 1) as part of doctoral research at the University of Queensland. The model has been used to provide new insights and quantitative knowledge of the alongshore and cross-shore evolutionary behaviour of the coastline associated with the large-scale sea level change that occurred during the late Pleistocene-Holocene period. Survey data recorded at the Gold Coast (Figure 1) over the period from 1966 to date was used in the research to investigate shoreward sand transport processes for application in the model.

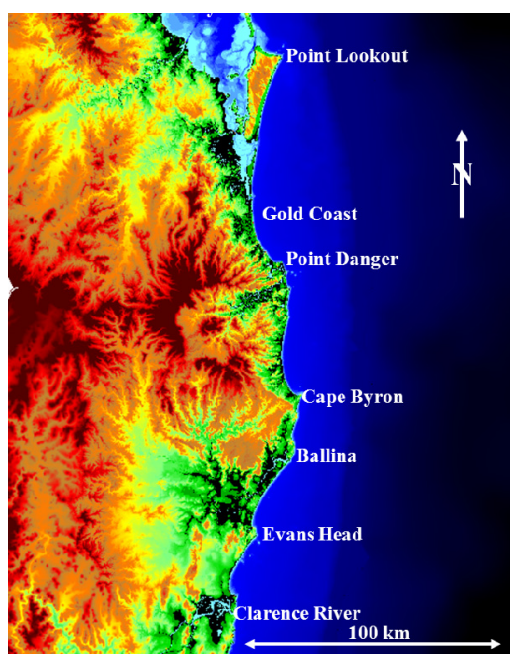

Figure 1. Australia's central east coast study region and Gold Coast location.

\section{Significance of Shoreward Sand Transport outside the Surfzone}

While cross-shore sand transport at ocean beaches is typically dominated by exchanges of sand between the beach and the immediate nearshore zone during storm wave events, a key factor in the long term evolution of the shoreline is the shoreward supply of sand from the continental shelf. This is

\footnotetext{
${ }^{1}$ University of Queensland / BMTWBM Pty Ltd, Brisbane, Australia
} 
of particular importance during the large-scale sea level changes that have occurred in the past, moving large quantities of sand that now form the Pleistocene and Holocene dune barriers and contemporary active beach system. It remains largely unknown whether or not there is any present day residual shoreward supply to the coastline from the lower shore-face or inner shelf, though this has been suggested on the basis of geomorphological considerations (Roy 1998; Cowell et al 2001). The significance of this is that even a quite minor supply, for example $1-2 \mathrm{~m}^{3} / \mathrm{m} / \mathrm{yr}$, may offset potential shoreline erosion due to longshore transport gradients over long coastline compartments.

During storm event erosion, sand is taken offshore from the beach to the nearshore region within and somewhat beyond the storm wave surf zone, often forming one or more shore-parallel bars. Subsequent beach re-accretion occurs over a longer time-frame (months to years) as the lower modal waves transport the sand shoreward to and through the surf zone, with wind-induced transport rebuilding the dune. While these processes may involve large exchanges of sand, erosion and accretion volumes associated with storm events are typically in balance, with dynamic stability or equilibrium over the longer term. Nevertheless, it is of importance to predict the rate of shoreward bar migration following severe erosion and the behaviour of beach nourishment sand that may be placed nearshore rather than directly on the upper beach.

\section{New Model Framework}

The framework for the new coastline evolution model provides for the large-scale sea level change that occurred during the last glacial period since 120,000 years before present, as well as both the associated longshore sand transport and substantial shoreward movement of sand to the coast from the $25-35 \mathrm{~km}$ wide continental shelf. The model framework is structured to represent the upper littoral zone and beach/dune part of the profile in terms of the conventional one-line schematization in which the shoreline position $(x)$ translates with horizontally constant shape relative to the prevailing sea level in accordance with Eq. 1 while the lower shore-face and continental shelf profile evolves freely in response to gradients in cross-shore transport there (Figure 2) using Eq. 2.

$$
\frac{\partial x}{\partial t}+\frac{1}{\left(D_{d}+D_{c}\right)}\left[\frac{\partial Q_{y}}{\partial y}-q-q_{o n}\right]=0
$$

where $Q_{y}$ is the longshore transport rate, $q$ is the net gain of sand from external sources and $q_{o n}$ is the supply of sand from the shore-face to the littoral zone.

$$
\frac{\partial z}{\partial t}=-\frac{\partial q_{x}}{\partial x}-\frac{\partial q_{y}}{\partial y}
$$

where $z$ is the bed level change, $q_{x}$ is the shoreward cross-shore transport in the direction of wave propagation and $q_{y}$ is the longshore transport below the littoral zone.

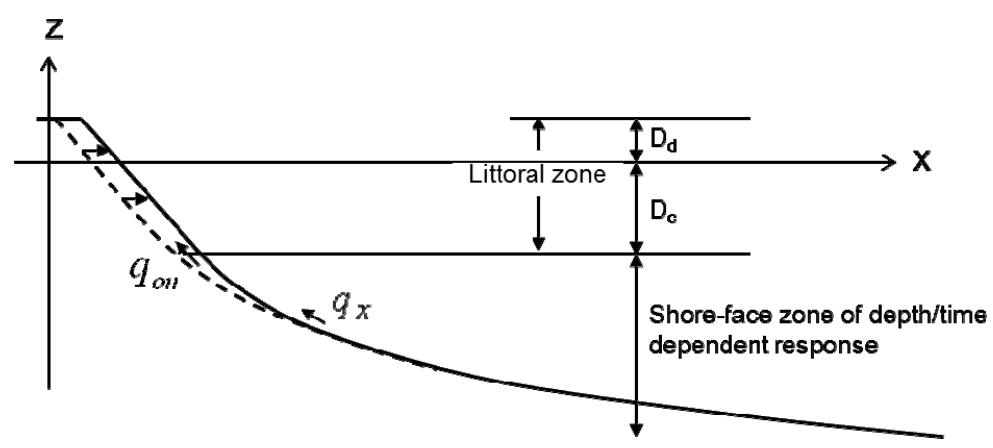

Figure 2. Schematized profile evolution.

It is assumed in the model setup that $Q_{y}$ occurs within the littoral zone above depth $D_{c}$ (Figure 2) and, while there may be a component of the shoreward transport $q_{x}$ in the longshore direction due to the wave angle to the depth contours, it is of negligible relative significance in the nearshore region and $\frac{\partial q_{y}}{\partial y}$ is adopted as zero below $D_{c}$. 


\section{SHOREWARD TRANSPORT RATES DERIVED FROM PROTOTYPE SURVEYS}

\section{Northern Gold Coast Profile Dynamics}

The database of surveys undertaken along the Gold Coast provides comprehensive information for analysis of beach system and profile evolution over a long period, commencing in 1966 and continuing to date. The survey data for the northern Gold Coast area (Figure 3) have been used to define the nearshore profile shapes and behaviour, with emphasis on processes occurring outside the surf zone region. It shows that the Gold Coast profiles generally exhibit a characteristic shape with an average shore-face bed slope of about $1^{\circ}(\sim 1 / 60)$, consistent with the slope at other locations along the east coast of Australia (Roy 2001). It transitions to the inner continental shelf slope typically over the depth range of 20-25m. Further, because the average shore-face profile shape remains constant over time with little or no change below the depth to which storm erosion modifies the profile, this indicates that a long term dynamic equilibrium exists there, in harmony with the prevailing wave climate and sand size (Figure 4).

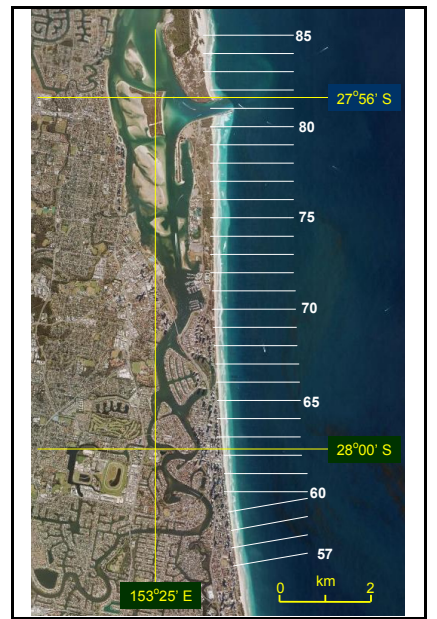

Figure 3. Location of northern Gold Coast survey profiles (ETA lines).

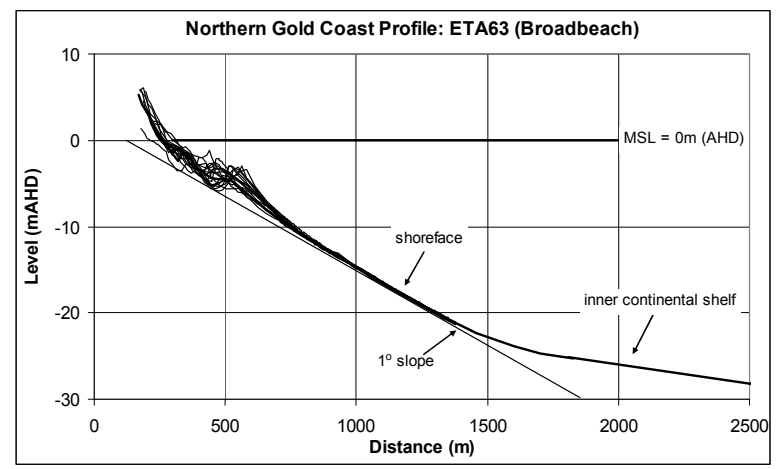

Figure 4. Typical Gold Coast nearshore profile shape.

However, a notable exception to the equilibrium profile shape occurs along the Spit (Figure 5), where historical movements of the Nerang River entrance have created an ebb delta lobe that is still evident after over 85 years up to $5 \mathrm{~km}$ south of the present entrance location. The lobe is interpreted from the 'bulge' shape of the profile that is markedly different from the equilibrium slope (Figure 6). Movement of the entrance from 1860 to 1970 is shown in Figure 5. The entrance was stabilised to form by training wall construction in 1985 (refer Figure 3), with sand bypassing of the longshore transport that has continued to date.

The depth and extent to which the lobe departs from the equilibrium shape increases with distance south from the present entrance, indicating progressive depletion over time as the entrance moved north. At survey line ETA 73 (Figure 3), the depth at which the lobe shape deviates from the equilibrium shape is about $12 \mathrm{~m}$. Further north at ETA 79, there remains a substantial bulge in the profile as shallow as $8 \mathrm{~m}$. 
Recession of the shoreline north from Narrowneck associated with the entrance movement was evident during 1950s when houses had to be relocated landward on their allotments because of threat by erosion.

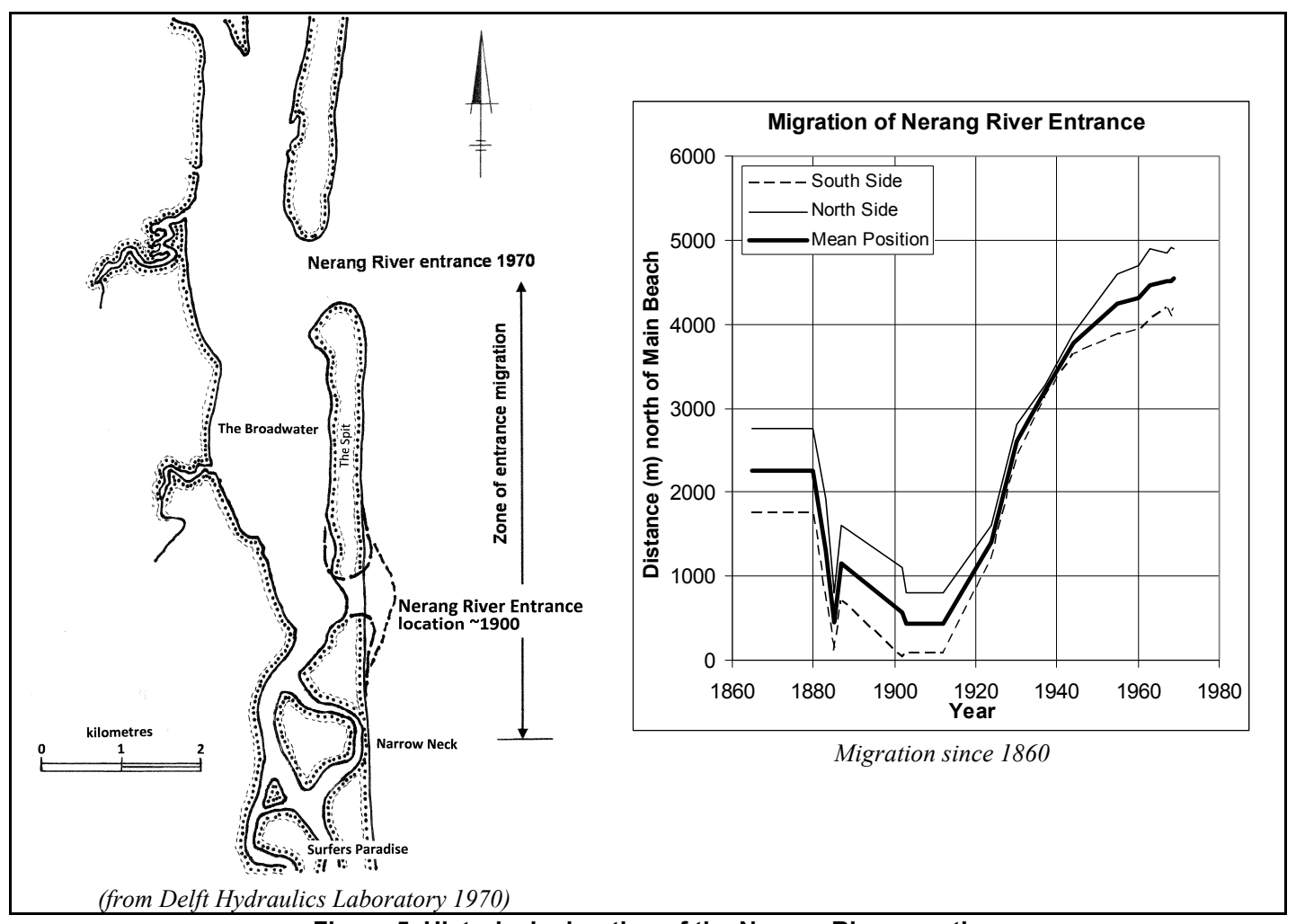

Figure 5. Historical migration of the Nerang River mouth.

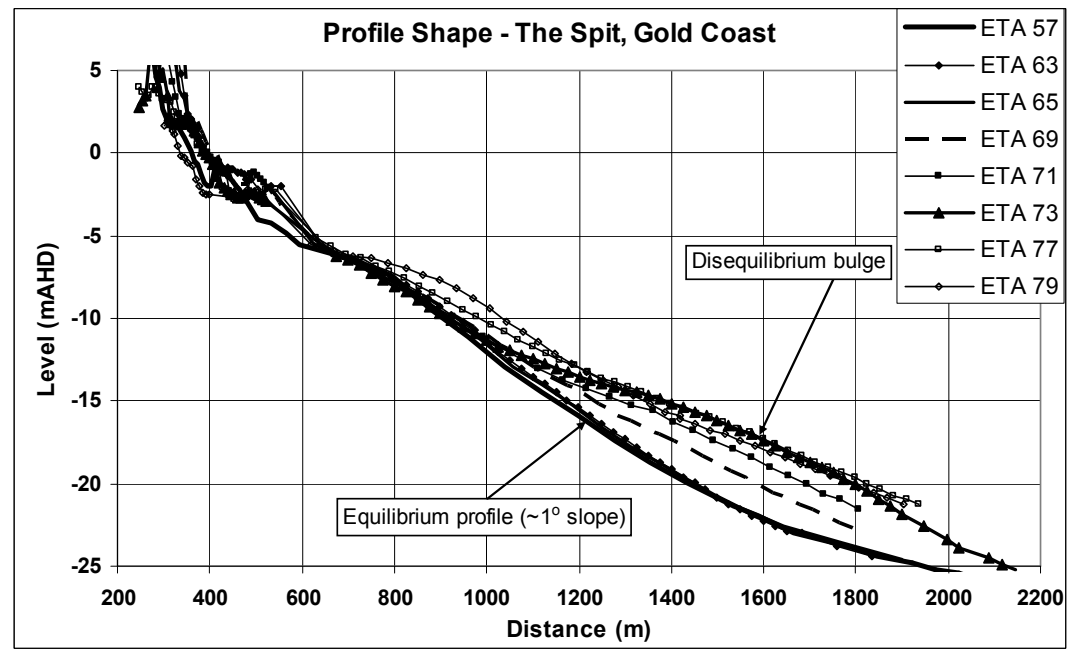

Figure 6. Disequilibrium lobe profiles at northern Gold Coast.

The profiles along the beach section ETA 57 to ETA 65 conform to the regional equilibrium shape and have been analysed to define the equilibrium bed slopes. The equilibrium profile shape may be defined in terms of bed slope $\left(S_{e q}\right)$ as a function of water depth $(h)$ given by Eq. 3 as the best fit to the data, as shown in Figure 7.

$$
S=0.0293-0.00095 h+0.000015 h^{2}
$$

This relationship is illustrated in Figure 8 in terms of its correlation with various adjacent profiles (ETA52 to ETA65). 


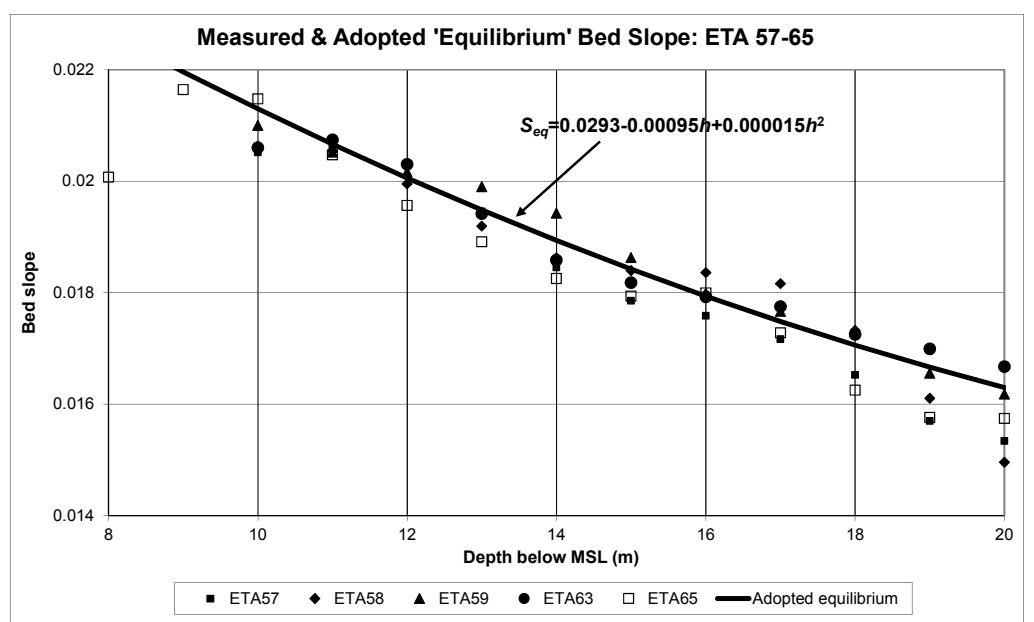

Figure 7. Disequilibrium lobe profiles at northern Gold Coast.

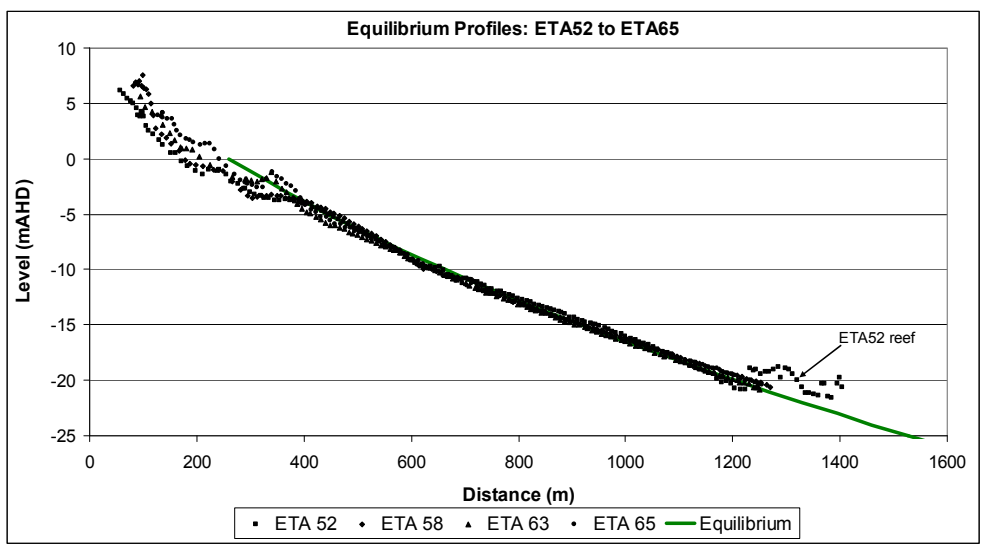

Figure 8. Equilibrium profiles at ETA 52 to ETA 65.

Correlation of the surveyed profiles with this equilibrium shape suggests a 4-part profile zonation based on response time (Figure 9) in which:

- the shallower parts at depth less than the Hallermeier (1977) littoral depth $\left(h_{\mathrm{L}}\right)$ respond relatively quickly (days to years);

- the mid to lower shore-face will adjust over a time scale of decades to centuries;

- the lower shore-face to inner shelf may remain out of equilibrium and continue to reflect their geological history even after centuries to millennia of evolution; and

- the geological history remains dominant across the transition and inner continental shelf areas.

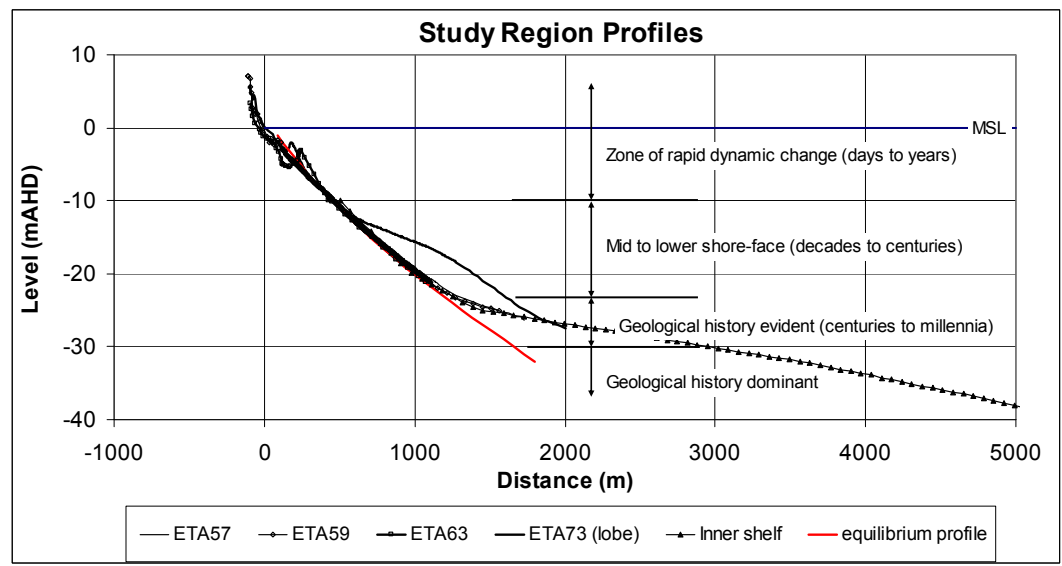

Figure 9. Profile zones based on morphologic response times. 
As can be seen, extrapolation of the adopted equilibrium profile deviates from the surveyed northern Gold Coast profiles at a depth of 22-25m, while the lobe extends to $25 \mathrm{~m}$. The Hallermeier (1981) depth indicator of the limit of potential net shoreward sand transport $\left(h_{\mathrm{i}}\right)$, calculated here to be about $30 \mathrm{~m}$, appears to be a reasonable estimate, where some shoreward sand transport may continue to occur while the response is very slow and the geological history remains evident.

\section{Disequilibrium Lobe Profile Evolution}

The profile bed slopes north from ETA 67 are in marked contrast to the equilibrium values further south as a result of the bulge shape there. The measured bed slopes there are shown in Figure 10.

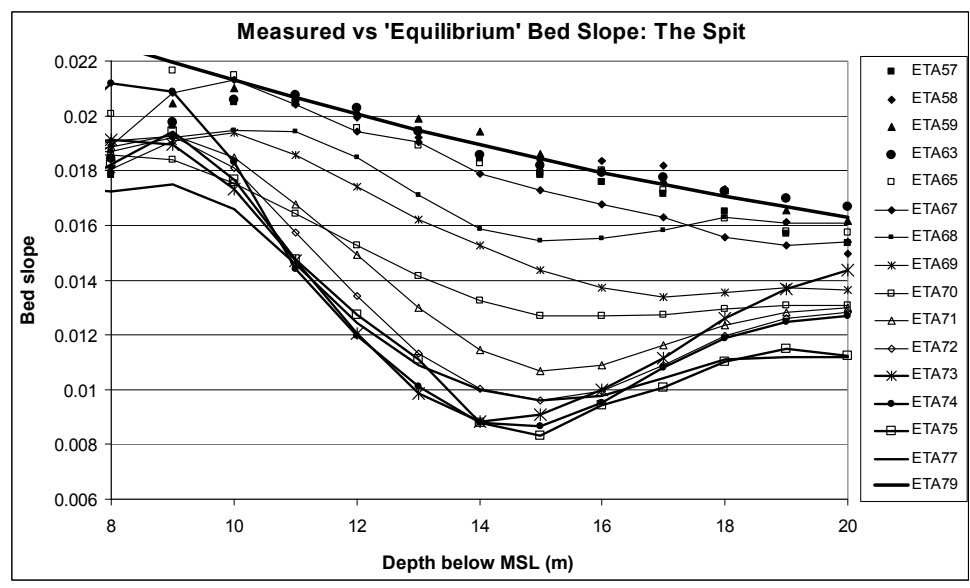

Figure 10. Disequilibrium profile bed slopes at ETA 67 to ETA 79.

It is expected that these profiles, both out of long term dynamic equilibrium and sufficiently shallow to be subject to potential net sand transport, would be altered progressively over time towards the equilibrium condition. The rate of change in the profile is expected to depend on both water depth as a dominant influence on waves and sand transport potential at the seabed and the extent to which the profile is out of equilibrium, as measured by the difference in bed slope from the equilibrium slope at any depth. Thus, at a location subject to a particular wave climate and with certain sand properties, profile disequilibrium will lead to a long term wave-induced net cross-shore sand transport and associated bed level changes that are both depth and slope dependent. The disequilibrium profiles along the Spit provide clear evidence of such behaviour, as illustrated in Figure 11.

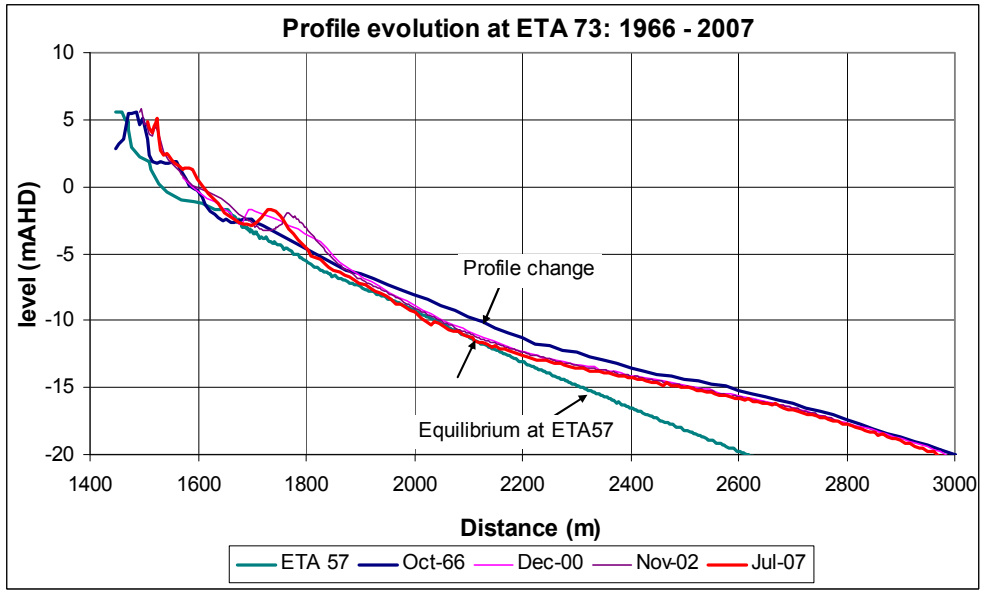

Figure 11. Profile evolution at dis-equilibrium lobe; 1966-2007.

To develop a quantitative relationship for cross-shore sand transport, analysis has been undertaken of the changes in the disequilibrium profiles along the Spit north from ETA 67 over the period 1966 to 2007. This analysis has determined the volumetric changes to the profiles below a range of water depths beyond 
the littoral zone depth where the storm bars form and little or no longshore movements of sand occur. These are interpreted to provide a measure of the shoreward sand transport rates at various depths.

The rates analysed from the data at a range of adjacent profiles are illustrated in Figure 12. The depth dependence indicates a shoreward supply of sand into the active upper profile of up to about 15$20 \mathrm{~m}^{3} / \mathrm{m} / \mathrm{yr}$ at $10 \mathrm{~m}$ depth north from ETA 72 , reducing progressively towards about $0.2-0.3 \mathrm{~m}^{3} / \mathrm{m} / \mathrm{yr}$ at $20 \mathrm{~m}$. The shoreward transport rates reduce markedly south from ETA 69 towards the area where the profiles are closer to equilibrium. The measured transport rate at ETA 59 is only about $2.0 \mathrm{~m}^{3} / \mathrm{m} / \mathrm{yr}$ at $10 \mathrm{~m}$ and diminishes markedly further seaward. Patterson (2007) showed that this shoreward supply of sand explained the shoreline stability along this section of coastline despite a marked positive gradient in the longshore transport rate there.

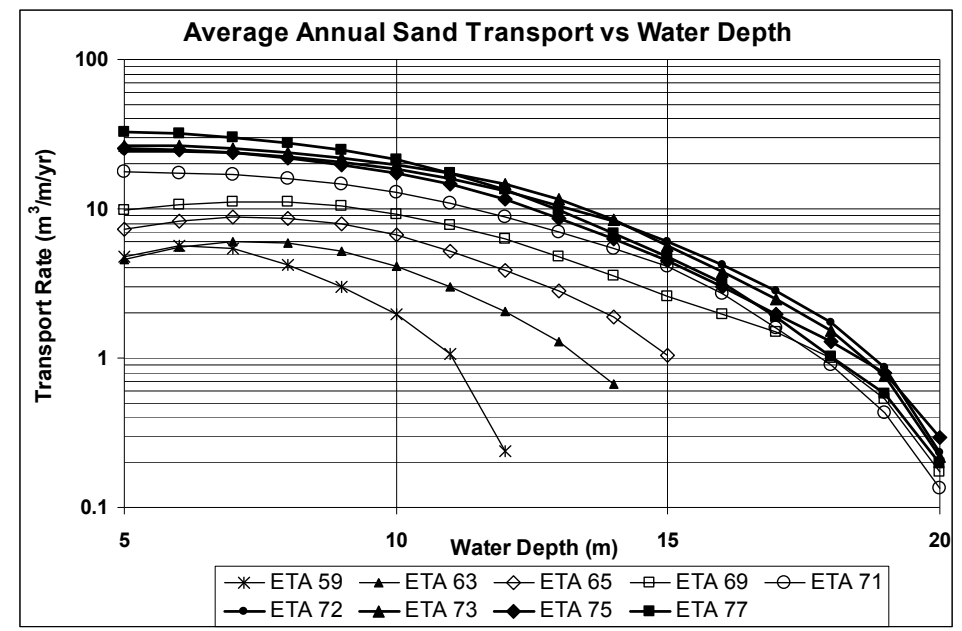

Figure 12. Measured shoreward sand transport; 1966-2007.

That the transport rates are not all similar at equivalent depths indicates that there may be bed slope dependence, as well as the evident depth dependence, that determines the net transport rate. The slope dependence has been explored on the basis of the measured transport rates at common depths for the varying profile shapes, as shown in Figure 13. This indicates a linear relationship between transport and bed slope at each depth and a progressive variation in the relationship with varying depth.

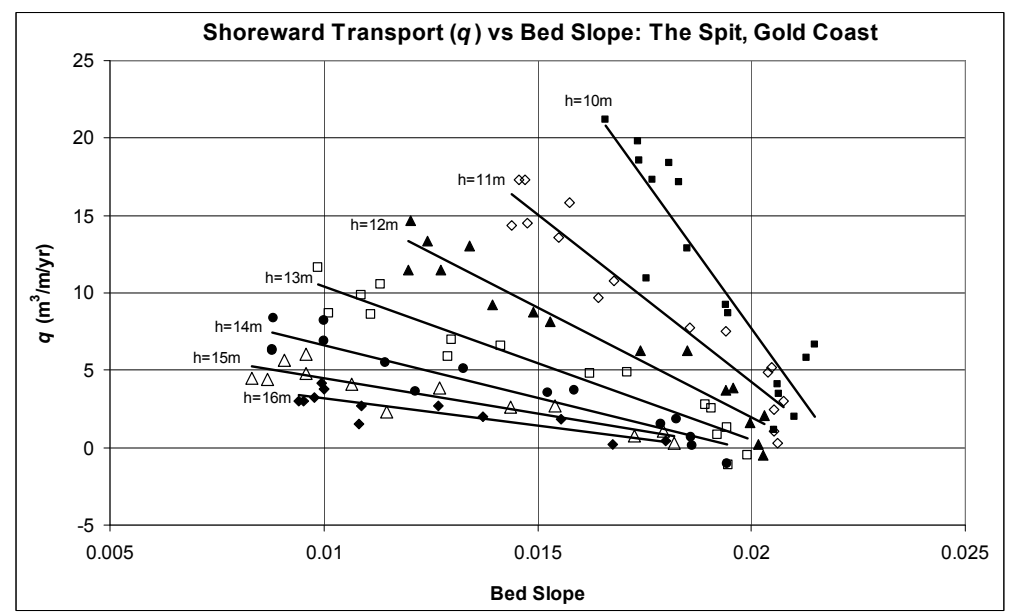

Figure 13. Shoreward sand transport versus bed slope.

\section{Potential Horizontal Bed Transport $\left(q_{p}\right)$}

To the extent that the linear fit relationships in Figure 13 may be extrapolated to their respective axes, they qualitatively correspond to a series of trend lines with their y axis intercept corresponding to the transport rates $\left(q_{H}\right)$ for zero bed slope and their x axis intercept corresponding to the bed slopes $\left(S_{e q}\right)$ for zero transport, taken to be the equilibrium slopes. These intercepts are listed in Table 2 . The equilibrium 
bed slope estimates are shown in Figure 14, together with the depth dependent equilibrium profile slopes given by Equation (3) derived from direct fitting to the profile data. While of similar order and trend with depth, the values derived from Figure 13 are somewhat lower than those measured directly. This may be due to errors in the derivation procedures or the likelihood that the Gold Coast may experience a small but significant net shoreward supply of sand from the inner continental shelf.

\begin{tabular}{|c|c|c|}
\hline \multicolumn{3}{|c|}{ Table 1. $\mathbf{x}$ axis $\left(\boldsymbol{S}_{e q}\right)$ and y axis $\left(q_{p}\right)$ intercepts from Figure 11.} \\
\hline $\begin{array}{c}\text { Depth } \\
(\mathrm{m})\end{array}$ & $\begin{array}{c}\text { Y intercept }\left(q_{p}\right) \\
\left(\mathrm{m}^{3} / \mathrm{m} / \mathrm{yr}\right)\end{array}$ & X intercept $\left(S_{e q}\right)$ \\
\hline 10 & 84.36 & 0.0220 \\
11 & 47.53 & 0.02196 \\
12 & 30.34 & 0.02194 \\
13 & 20.28 & 0.02049 \\
14 & 13.47 & 0.01974 \\
15 & 9.07 & 0.01977 \\
16 & 6.65 & 0.01912 \\
\hline
\end{tabular}

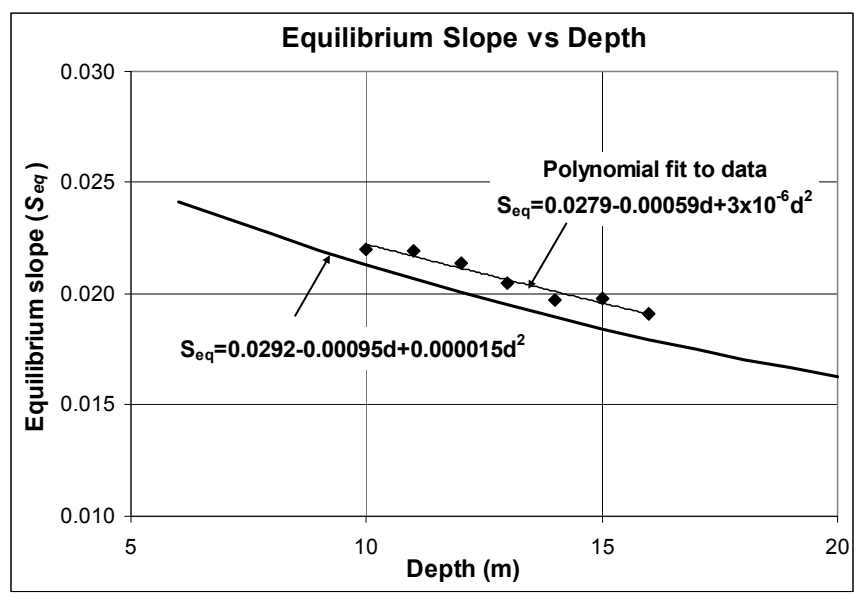

Figure 14. Equilibrium bed slopes derived from Figure 13.

Similarly, the potential horizontal bed transport rates $\left(q_{H}\right)$ have been calculated from the measured transport rates based on the trend lines in Figure 13 using the y intercept $(S=0)$ values of transport (Table 1). A best fit function through the data has exponential form derived as:

$$
q_{H}=4986 \mathrm{e}^{-0.42 h}
$$

Equation (4) is shown in Figure 15 together with the measured transport data. This indicates potential horizontal bed transport rates significantly higher than the measured rates shown in Figure 12 , as would be expected where the transport has a bed slope dependence.

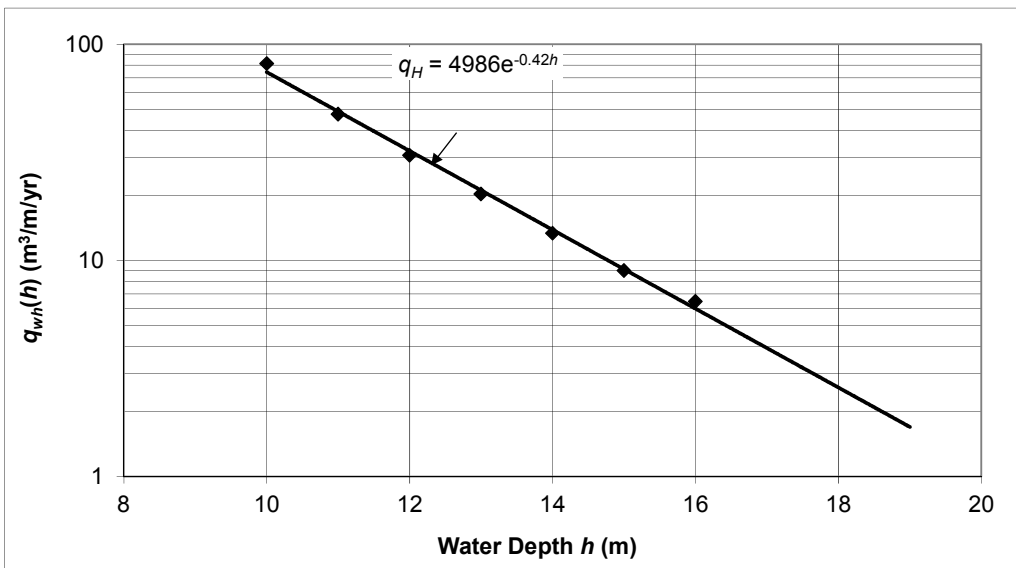

Figure 15. Potential horizontal bed transport rates derived from Figure 13. 


\section{Slope Dependence Relationship}

The linear trend lines in Figure 13 have the form:

$$
q_{S}=q_{H}-\frac{q_{H}}{S_{e q}} S
$$

That is:

$$
q_{s}=q_{H}\left[1-\frac{S}{S_{e q}}\right]
$$

The term in brackets represents the slope dependent term providing for bed slope such that the actual annual average net shoreward sand transport $\left(q_{s}\right)$ at any time is proportional to both a depth dependent potential annual average transport $\left(q_{H}\right)$ and the difference between the actual and equilibrium bed slopes at any depth. Conversely, the measured rates of transport may be used to calculate the equivalent horizontal bed transport rates using this bed slope factor, in the form:

$$
q_{H}=q_{s}\left(1-\frac{S}{S e q}\right)^{-1}
$$

The equivalent long term average potential (horizontal bed) transport rates $\left(q_{H}\right)$ as a function of water depth have been calculated directly from the measured transport rates, using the measured bed slopes and the adopted $S_{e q}$ from Eq. 3. The resulting transport rates are shown in Figure 16, together with Eq. 4, indicating close agreement between the results from the two methods of field data interpretation.

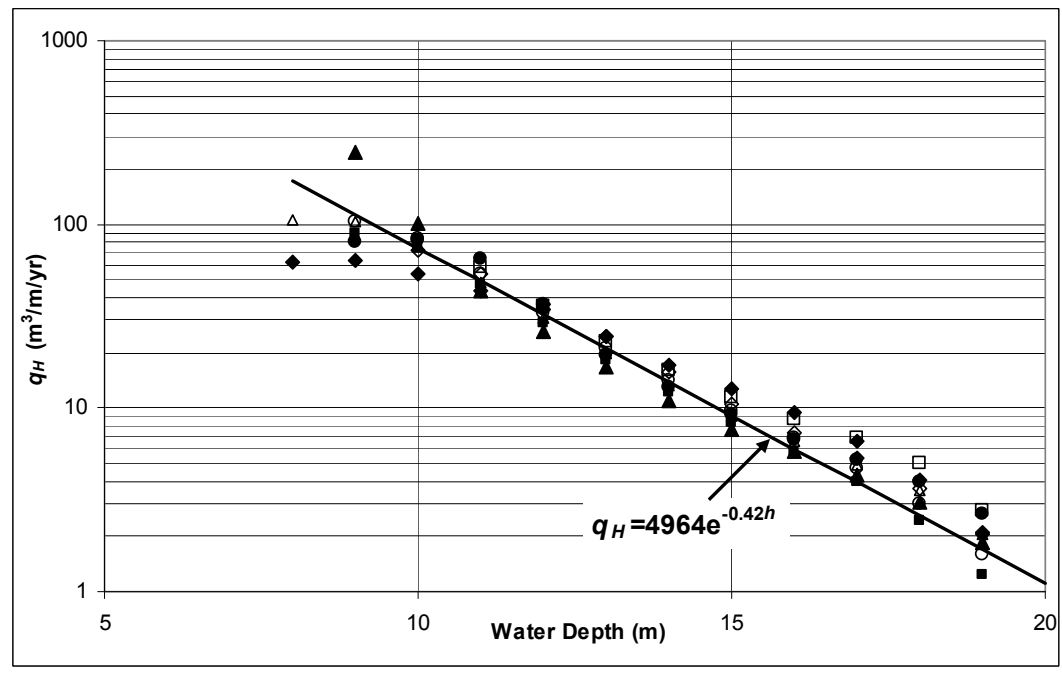

Figure 16. Potential horizontal bed transport rates derived from Eq. 7.

\section{PREDICTIVE METHOD BASED ON $\overline{u^{3}}$}

Ribberink and Al-Salem (1990) and Ribberink et al (1994) derived a relationship for time-averaged sand transport under non-breaking wave sheet flow conditions, based predominantly on wave tunnel tests for sediment of median grain size $0.21 \mathrm{~mm}$ as:

$$
q_{s}=0.00018 \overline{u^{3}} \quad[\text { bulk m} / \mathrm{m} / \mathrm{s}]
$$

While Eq. 8 does not differentiate the mode of transport, its derivation is based on measured net transport rates that include both bed load and suspended load for the experimental conditions tested. However, because it is based on tunnel tests, neither boundary layer streaming nor the Stoke's drift are incorporated in the forcing conditions. As well, it has been shown (Nielsen 1992; Nielsen \& Callaghan 2003; Teakle 2006) that this approach is inadequate because it does not include the effects of near bed flow acceleration.

Furthermore, its limitation to sheet flow conditions prohibits its application to the ripple regime. It is well known that, for example, vortex ripples may lead to net transport in the direction opposite to that of wave travel (Bijker et al 1976; Nielsen 1992). Thus, in the absence of a superimposed current, Eq. 8 will predict net transport that is always positive in the direction of wave travel, resulting only from asymmetry of the near-bed orbital current. 
The present research by the writer has utilised a range of available large wave flume test data to test the Ribberink and Al-Salem (1990) relationship for sheet flow under realistic simulated prototype conditions and extend it to cases with rippled beds. A parametric indicator of ripple bed effects was adopted as the mobility number ( $\psi$ ), shown by Nielsen (1992) to relate well to ripple height and steepness, leading to a modified transport relationship:

$$
q_{s}=c_{1} u^{3} f(\psi) \quad \text { [solid grain } \mathrm{m}^{3} / \mathrm{m} / \mathrm{s} \text { ] }
$$

The coefficient $c_{1}$ relates to transport under sheet flow conditions and $f(\psi)$ aims to provide an adjustment factor for the effects of ripples on the basis that their formation is strongly related to $\psi$ below values of about 300 (Nielsen 1981; Nielsen 1992). Adopting $f(\psi)=1$ for sheet flow conditions with $\psi$ $>300$ allows the value of $c_{1}$ to be determined directly from the measured flume data. It is then feasible to determine $f(\psi)$ from other rippled bed flume data with $\psi<300$ as:

$$
f(\psi)=\frac{q_{s}}{c_{1} u^{3}}
$$

Wave flume experiments for sheet flow as described in Ribberink et al (2000), Dohmen-Janssen and Hanes (2002) and Schretlen et al (2010) were used as the basis for determining $c_{l}$. The wave flume data of Roelvink (1988) and Hurther \& Thorne (2011) for rippled beds provide the basis for $f(\psi)$. For this analysis, the adopted values of $\overline{u^{3}}$ are based on values derived from the high order wave theory of Fenton (1988), with zero Eulerian net free stream current outside the boundary layer to filter out effects of the Stokes drift, but include provision for the average boundary layer streaming velocity, adopted as $0.375 U^{2} / c$. This yields $c_{l}=0.00019$ for $q_{s}$ in $\mathrm{m}^{3} / \mathrm{m} / \mathrm{s}$, close to the coefficient of Ribberink and Al-Salem (1990), as shown in Figure 17, and $f(\psi)$.illustrated in Figure 18 derived empirically for $\psi<300$ as:

$$
f(\psi)=1-\left[\frac{500-\psi}{450}\right]^{4.5}
$$

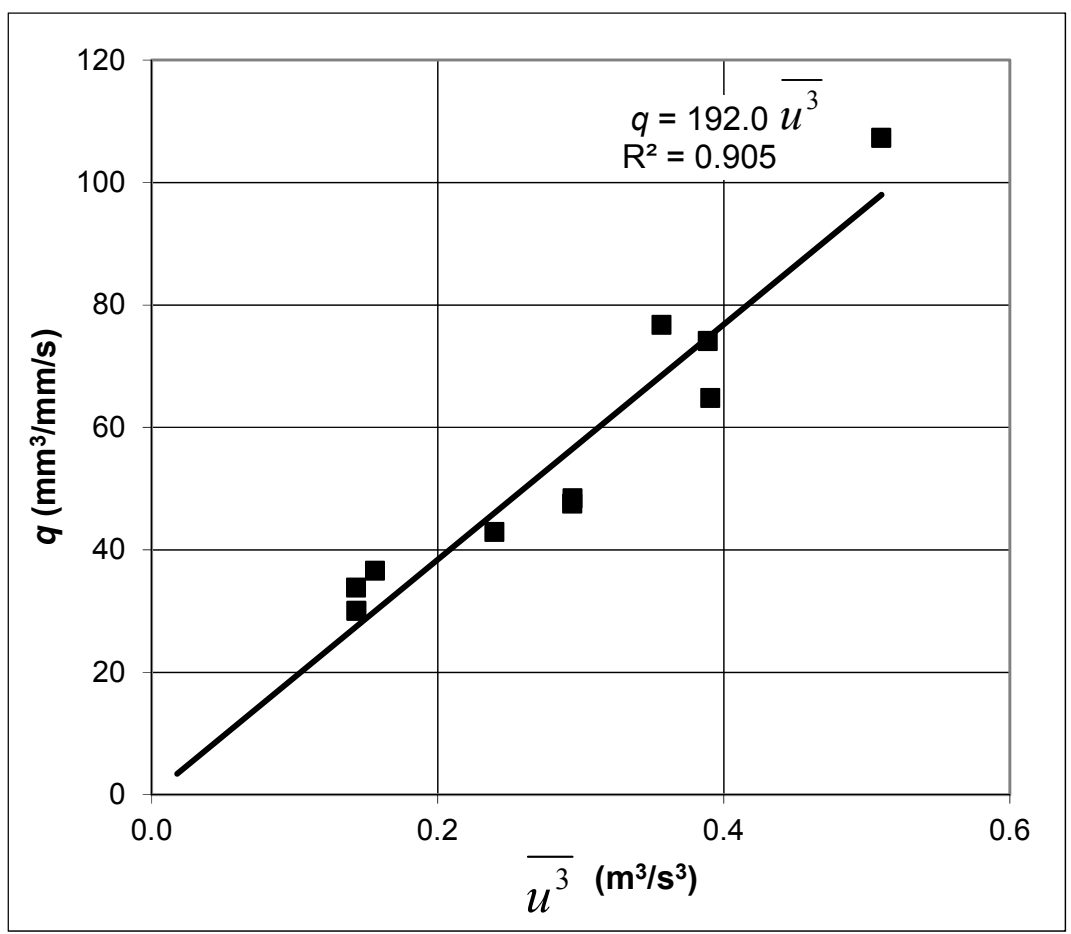

Figure 17. Sheet flow wave flume data analysis of $c_{1}$. 


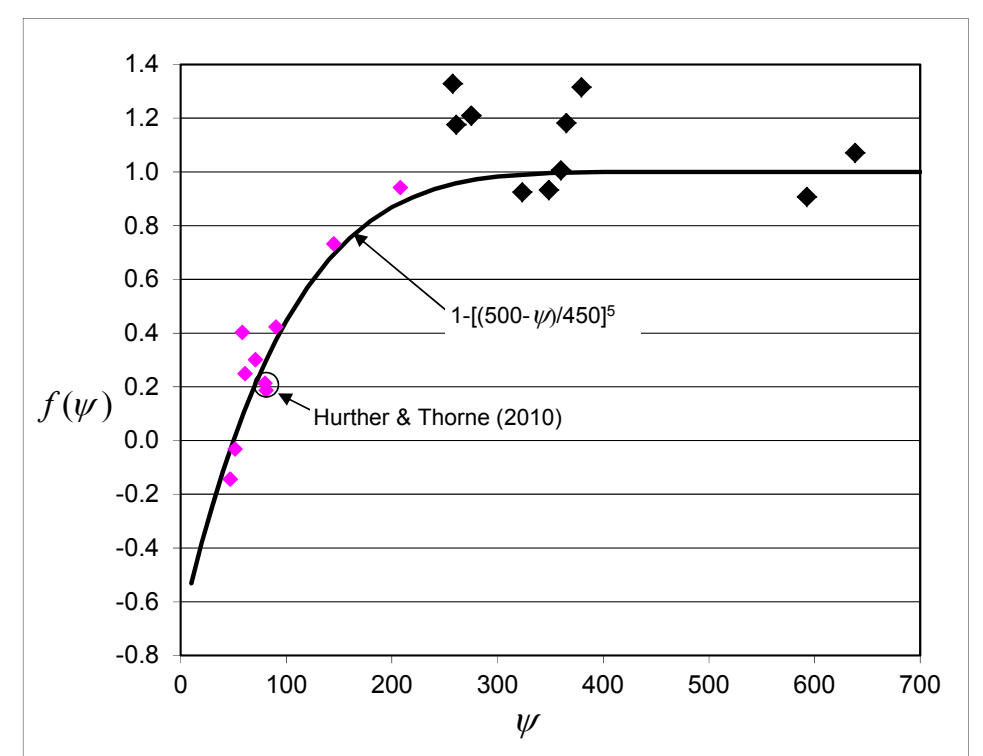

Figure 17. Rippled bed wave flume data (pink) analysis of $f(\psi)$.

\section{APPLICATION OF PREDICTION RELATIONSHIPS}

\section{Potential Horizontal Bed Transport}

Eq. 9 has been used to calculate the annual average horizontal bed shoreward transport rates for a range of water depths using wave data in time series form recorded in $25 \mathrm{~m}$ depth immediately offshore from the northern Gold Coast study site. Typical time series rates are shown in Figure 19, calculated for $8 \mathrm{~m}$ depth, illustrating the dependence on wave conditions with high rates occurring during high long period swell waves. The resulting annual average transport rates for varying depth are shown in Figure 20, together with Eq. 4 and the measured data transposed using Eq. 7, indicating quite close agreement. This confirms that either method could be used with some confidence to provide the depthdependent potential horizontal bed transport rates, which may be applied in combination with Equation (6) to estimate the depth/slope-dependent cross-shore transport rates at this location.

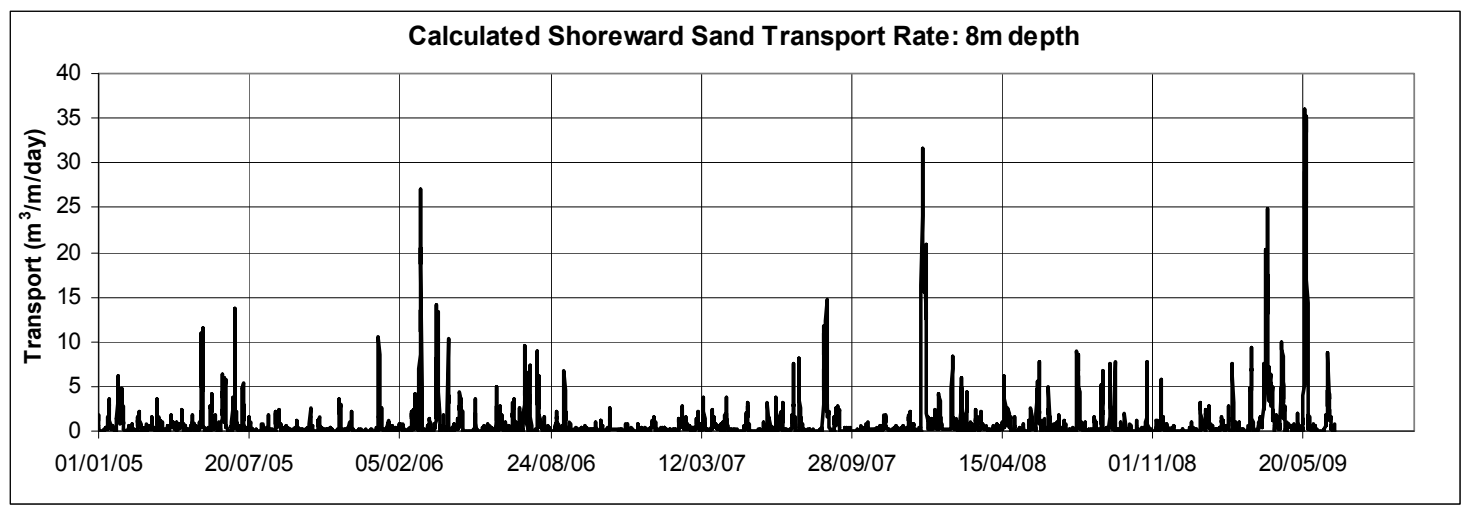

Figure 19. Calculated time series of shoreward sand transport at $8 \mathrm{~m}$ depth using Eq. 9. 


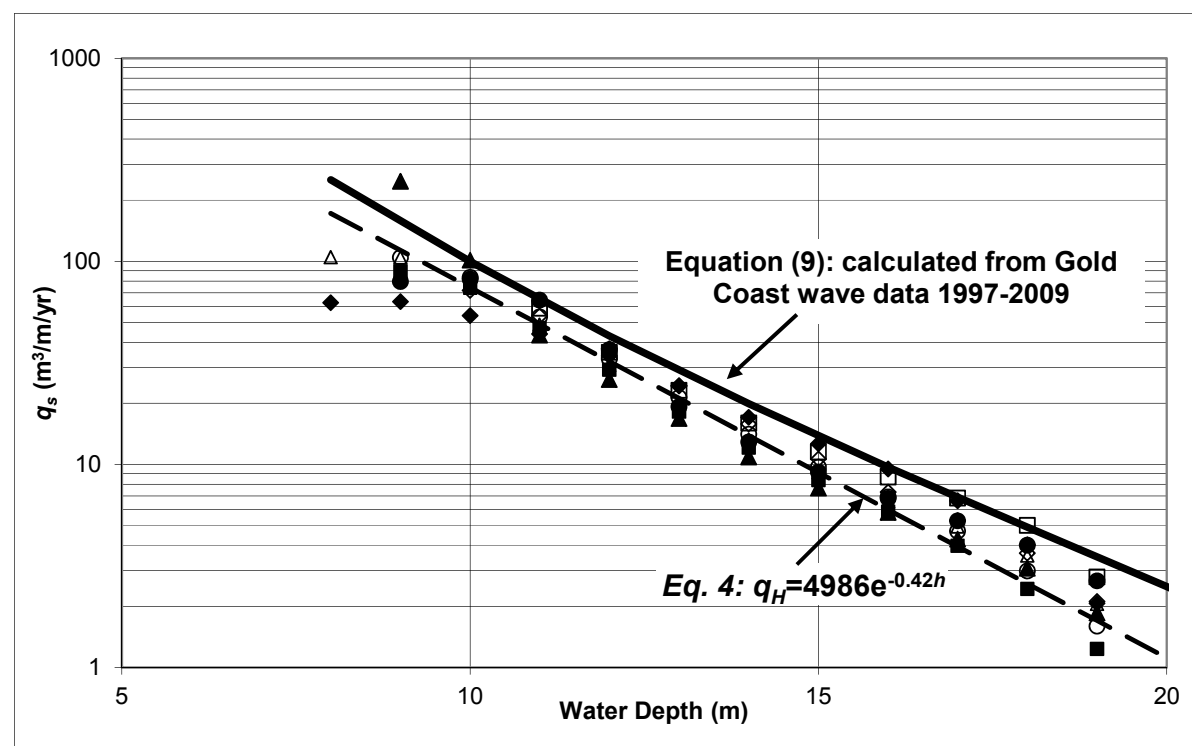

Figure 20. Horizontal bed transport from Eq. 9 compared to Eq. 4 and measured data transposed by Eq. 7.

The advantage of using Equation (9) is the potential ability to transfer the method to other locations with different wave conditions, provided the equilibrium profile bed slopes can be defined, or to model specific wave cases. There remains a significant knowledge gap in that approach for large wave events that cause substantial beach erosion with counter-balancing seaward suspended load transport at depths that the Gold Coast data shows extend beyond $10 \mathrm{~m}$.

\section{Model Simulation of Northern Gold Coast Lobe Evolution}

The northern Gold Coast lobe evolution for the 41 year period 1966 to 2007 has been tested in the model to validate its capability with respect to the measured data and the influence of the depth-slope dependence on the shoreward transport. Additionally, the test has been extended over a longer period of 5,000 years, equivalent to the Holocene period for which the sea has been approximately at its present level, to assess the depth limitation on profile evolution at the base of the shore-face and transition to the inner continental shelf.

Figure 21 shows the 41 year simulation and Figure 22 the result of its extension over 5,000 years. This confirms that the model is reproducing the profile history and that its evolution towards equilibrium will continue in the form of progressive deepening towards the equilibrium shape. Also shown in Figure 21 are the adopted equilibrium shape and the surveyed profile at ETA 58 and ETA 63. The model result shown as the pink line in Figure 22 is at 3,000 years, predicting that the further change occurring after that time is extremely slow. The predicted 5,000 year profile shape departs from the equilibrium shape below about $20 \mathrm{~m}$. Notably, it corresponds reasonably well with the surveyed profiles in the depth range of transition from the equilibrium lower shore-face profile to the inner shelf profile.

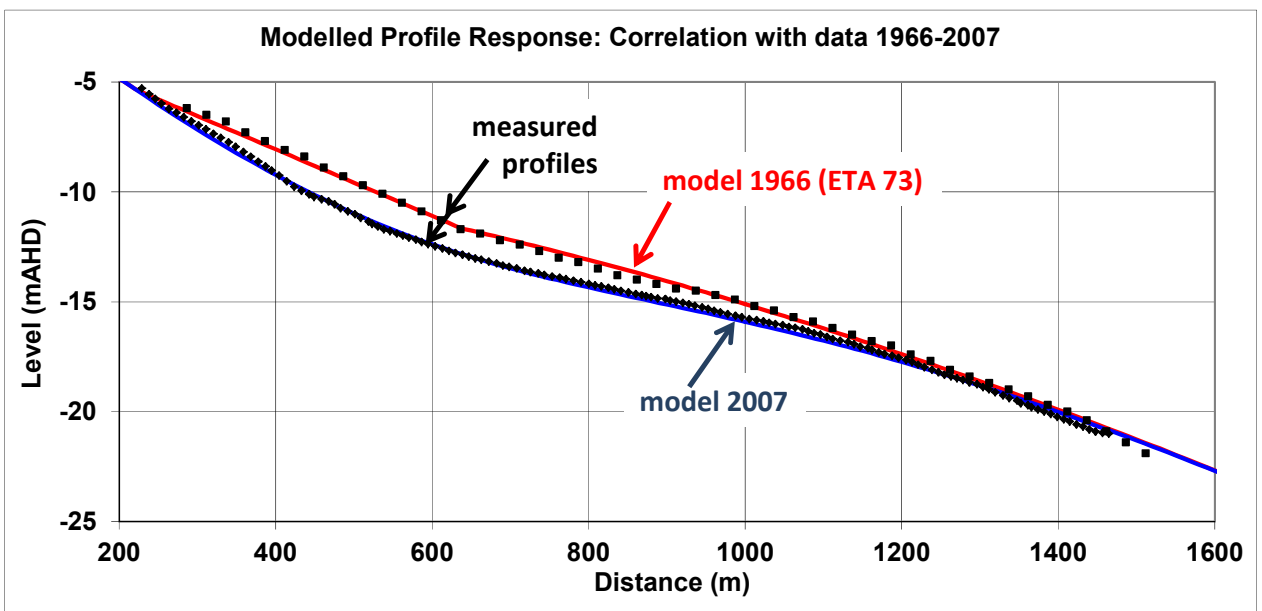

Figure 21. Modelled and measured lobe evolution for the period 1966 to 2007. 


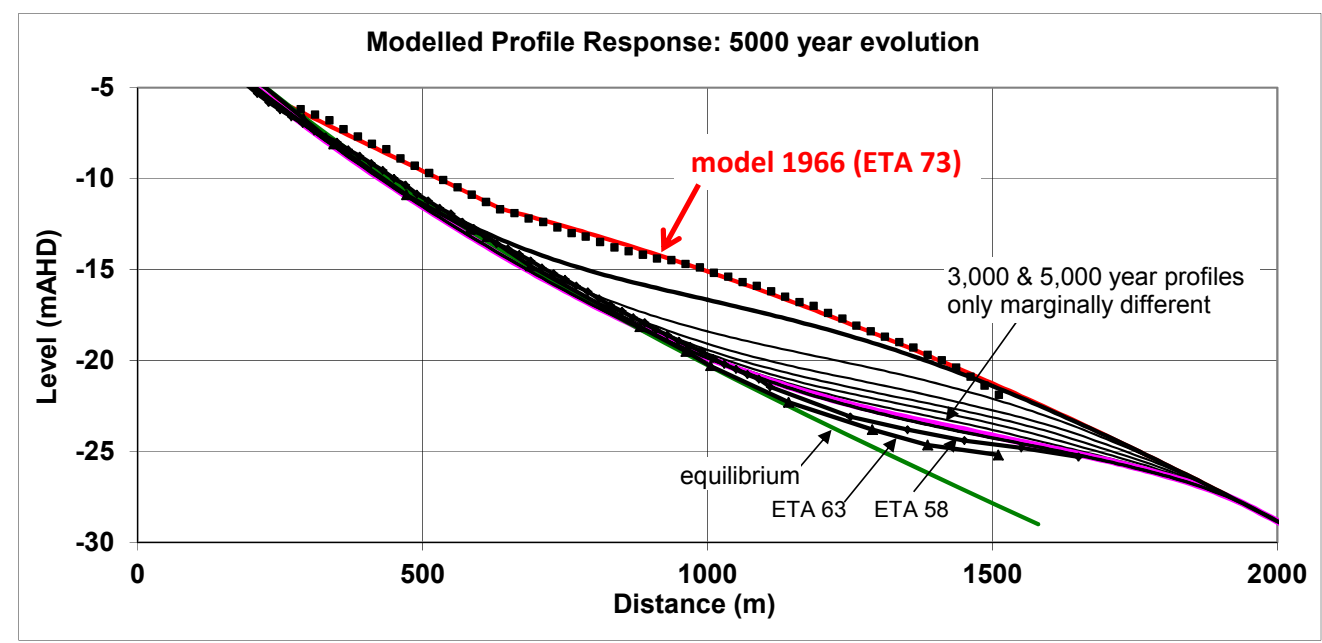

Figure 22. Modelled lobe evolution over 5,000 years.

Figure 23 shows the modelled reduction in the shoreward sand supply rate at a depth of $10 \mathrm{~m}$ over the longer term. It reduces from the 41 year initial average of about $25 \mathrm{~m}^{3} / \mathrm{m} / \mathrm{yr}$ for 1966 to 2007 to $2 \mathrm{~m}^{3} / \mathrm{m} / \mathrm{yr}$ over 500 years and approaches about $0.65 \mathrm{~m}^{3} / \mathrm{m} / \mathrm{yr}$ over the very long term. This latter rate is the rate of ongoing shoreward supply from the inner continental shelf to the shore-face predicted by the model.

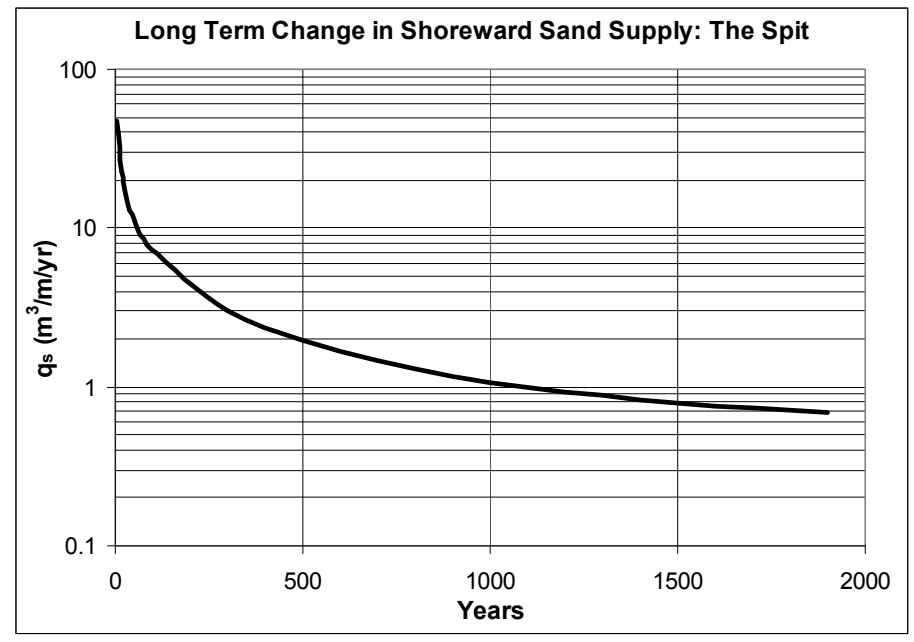

Figure 23. Modelled long term reduction in shoreward sand supply at the northern Gold Coast lobe.

\section{Profile Evolution Time Scale (ts)}

Eq. 4 gives an estimate of the depth dependence relationship for the long term average potential transport $q_{h}$, derived from the surveyed morphology. This may be used to determine the depth dependent time scale $(t s)$ of profile evolution at various depths $(h)$ in a relative sense, given as:

$$
\frac{t s_{h 2}}{t s_{h 1}}=e^{0.42(h 2-h 1)}
$$

Thus it can be shown that, for example, the time scale at $20 \mathrm{~m}$ depth is about 110 times greater than that at $8 \mathrm{~m}$ depth. Further, the available surveyed profile data for Gold Coast cyclone erosion recovery indicates that the time scale of shoreward return of sand from a depth of about $5 \mathrm{~m}$ following erosion events is (order of) 6 months, consistent with the finding of Corbella \& Stretch (2011) for the east coast of South Africa. Adopting $t s_{5}=0.5$ years:

$$
t s_{h}=0.5 e^{0.42(h-5)}
$$

Eq. 13 is illustrated in Figure 24. This suggests an equivalent response time of 4 years at 10m, 300 years at $20 \mathrm{~m}$ and millennia for water depths greater than about $23 \mathrm{~m}$. The time scale extends to in excess of 6,000 years at $>27-28 \mathrm{~m}$ depth, the duration of profile evolution at present sea level. 


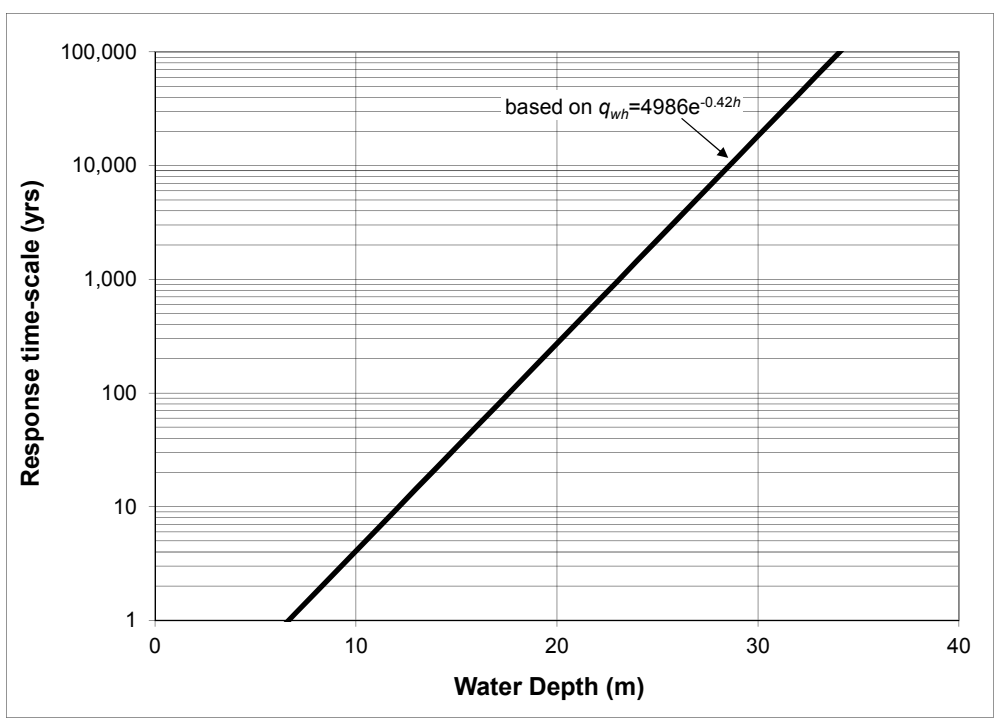

Figure 24. Depth dependent profile response time-scale.

This has significance for application to assessment of the effects of sea level rise of predictive methods such as the 'Bruun Rule' (Bruun 1962; 1986) and shore-face translation models (Cowell et al 1992), which assume that the shore-face translates in its geometrical equilibrium shape to an adopted depth of closure within the time scale of the sea level change. Specifically, this significance relates to:

- The need to define the shape of the shore-face equilibrium profile properly, not to include the transition and inner shelf regions where there is generally some residual shoreward sand transport even after (circa) 6,000 years of profile evolution; and

- Utilisation of a closure depth that is commensurate with the profile response time-scale.

\section{DISCUSSION}

This research has provided a means of quantifying the shoreward supply of sand and profile evolution across the shore-face and inner continental shelf. A database of long term surveys documenting progressive shore-face profile evolution has been analysed to provide annual average rates of shoreward sand supply under the wave conditions prevailing at the northern Gold Coast. Additionally, analysis of large wave flume data has been used to derive an empirical transport relationship to cater for the range of prevailing conditions known to be important factors affecting sand transport under non-breaking waves, including sheet flow and rippled bed regimes and wave boundary layer streaming. This may then be applied to modelling incorporating both alongshore and cross-shore sand transport processes, together with major sea level change, more generally at locations with different wave climate to that at the Gold Coast.

However, despite the progress made with development of empirical models for both long term average and wave-dependent instantaneous rates of shoreward transport, considerable gaps in knowledge of these processes remain. It is recognised that analysis methods based on the fundamental physics involved continue to be an elusive aim of researchers worldwide. Nevertheless, this research has shown that large wave flume experiments together with analysis of suitable comprehensive prototype survey data offer opportunities to develop theoretical and/or empirical methods that have practical application to modelling procedures.

\section{ACKNOWLEDGMENTS}

I acknowledge and thank the Queensland Department of Environment and Resource Management and the New South Wales (then) Department of Environment and Climate Change for access to wave and survey data used extensively in this research.

\section{REFERENCES}

Bijker E.W., E. van Hijum and P. Vellinga 1976. Sand transport by waves. Coastal Engineering, 1976 pp 1149-1167.

Bruun, P. 1962. "Sea Level Rise as a Cause of Shoreline Erosion". Journal of Waterways and Harbours Division, American Society Civil Engineering, 88: 117-130. 
Bruun P. 1986. The Bruun Rule of erosion by sea-level rise: A discussion on large scale two and threedimensional usages. Journal of Coastal Research, 4(4), 527-648. Charlotteville.

Corbella, S. and D.D. Stretch 2011. Shoreline recovery from storms on the east coast of South Africa. Nat. Hazards Earth Syst. Sci., 2011.

Cowell, P.J., P.S. Roy and R.A. Jones 1992. Shoreface translation model: Computer simulation of coastal sand body response to sea level rise. Mathematics and Computers in Simulation 33 (1992), pp603-608, Elsevier Science Publishers B.V.

Cowell, P.J., M. Stive, P.S. Roy, G.M. Kaminsky, M.C. Buijsman, B.G. Thom and L.D. Wright 2001. Shoreface sand supply to beaches. Proc. $27^{\text {th }}$ International Conference on Coastal Engineering, ASCE, 2496-2508.

Dohmen-Janssen, C.M. 2000. Sheet flow under monochromatic waves and large wave groups - CCM measurements in the large wave flume, Hannover. University of Twente, Civil Engineering and Management, Report 2000R-003/MICS-012.

Fenton, J. 1988. The numerical solution of steady water wave problems, Computers and Geosciences 14, 357-368.

Hallermeier, R.J. 1977. Calculating a yearly limit depth to beach erosion. Proc. $16^{\text {th }}$ Coastal Engineering Conf., Hamburg, Germany, pp 1493-1512.

Hallermeier, R.J. 1981. A profile zonation for seasonal sand beaches from wave climate. Coastal Engineering., 4, pp. 253-277.

Hurther, D. and P.D. Thorne 2011. Suspension and bedload sediment transportprocesses above a migrating sand rippled bed under shoaling waves. Journal of Geophysical Research, 116, C07001, doi:10.1029/2010JC006774.

Nielsen, P. 1981. Dynamics and geometry of wave-generated ripples. Journal of Geophysical Research, Vol 86, No C7, pp 6467-6472.

Nielsen, P. 1992. Coastal bottom boundary layers and sediment transport. Advanced series on Coastal Engineering - Volume 4, World Scientific Publishing Co. Pte. Ltd., Published 1992.

Nielsen, P. and D.P. Callaghan 2003. Shear stress and sediment transport calculations for sheet flow under waves. Coastal Engineering, 47(3): 347-354.

Patterson, D.C. 2007. Sand transport and shoreline evolution, Northern Gold Coast, Australia”. Journal of Coastal Research, Special Issue 50.

Ribberink, J.S. 1998, Bed load transport for steady flows and unsteady iscillatory flows. Coastal Engineering, 34 (1998) 59-82, Elsevier Science B.V.

Ribberink J.S. and Al-Salem A. (1990). Bed forms, sediment concentration and sediment transport in simulated wave conditions. Proc. $22^{\text {nd }}$ International Conference on Coastal Engineering, ASCE, Delft, pp 2318-2331.

Ribberink, J.S., I. Katopodi, K.A.H. Ramadan, R. Koelewijn and S. Longo 1994. Sediment transport under (non)-linear waves and currents. Proc. $24^{\text {th }}$ International Conference on Coastal Engineering, ASCE, Kobe, Japan.

Ribberink, J.S., C.M. Dohmen-Janssen, D.M. Hanes, S.R McLean and C. Vincent 2000. Near-bed sand transport mechanisms under waves - a large-scale flume experiment (Sistex 99). Proc 27th Inernationalt Conference on Coastal Engineering, ASCE, Sydney, pp. 3263-3276.

Roelvink, D. 1988. Large-scale cross-shore transport tests. Report H596, Delft Hydraulics, Delft, Netherlands.

Roy, P.S. 1998. Cainozoic geology of the New South Wales coast and shelf. In E. Scheibner (ed. H. Basden), Geology of New South Wales - Syntheses, Volume 2, Geological Evolution: Precambrian to Present. New South Wales Geological Survey, Australian Memoir, Geology, Volume 13(2), 361385.

Roy, P.S. 2001. Sand deposits of the NSW inner continental shelf. Geoscience Surveys report, NSW, Australia.

Schretlen J.J.L.M., J.S. Ribberink and T. Donoghue 2010. Boundary layer flow and sand transport under full scale surface waves. Coastal Engineering 2010.

Teakle, I. 2006. Coastal boundary layer and sediment transport modelling, PhD thesis, University of Queensland. 